\section{Múltiples identidades narrativas en el espacio teatral}

Andrea Mardikian *

\begin{abstract}
Resumen: Buenos Aires es una de las capitales culturales del mundo. Los datos oficiales muestran que existen seis salas que dependen del Estado, doce salas privadas comerciales y más de doscientos espacios de teatro independiente, de los cuales más del setenta por ciento funcionan en sitios no convencionales. Según Antonio Gramsci, la hegemonía es una estructura ideológica, discursiva, estética que legitima el statu quo, en un momento histórico, político y cultural determinado. Por lo tanto, la hegemonía legitima ciertas ideologías y discursos expresivos por encima de otros. El circuito oficial y comercial del teatro responde a modelos hegemónicos. Sin embargo, se identifica una ostensible producción de teatro y espacios independientes. Es necesario reformular el concepto de teatro 'independiente' de Leónidas Barletta. En la actualidad, el Instituto Nacional del Teatro, Proteatro y el Fondo Nacional de las Artes subsidia y financia aquellos proyectos teatrales 'independientes'. De esa manera, los mismos portan una autonomía relativa, regida por las leyes de selección de estas Instituciones, transformándose en 'alternativos' más que en 'independientes'. El off del off surge como una forma espectral del circuito 'alternativo'. Los espacios son viviendas de los directores y actores, galpones u otros lugares que no cumplen con los requisitos de habilitación de un teatro. El objetivo del artículo es describir y articular un pensamiento crítico sobre la identidad del espacio teatral de la Ciudad. El punto nodal es la teoría de identidad de Paul Ricoer que piensa la identidad personal como una identidad narrativa. La hipótesis del ensayo descansa en la siguiente predicción: El 'circuito teatral' ya no puede definirse bajo la lógica del pensamiento binario. Es necesario recurrir al pensamiento deconstructivista para reflexionar sobre el espacio teatral actual.
\end{abstract}

Palabras clave: Brecha de Paralaje - forma espectral - hegemonía- identidad - identidades narrativas - instituciones legitimadoras - múltiples identidades - teatro alternativo - teatro comercial - teatro independiente - teatro off del off - teatro oficial.

[Resúmenes en inglés y portugués en las páginas 212-213]

${ }^{(*)}$ Licenciada en Artes (Orientación Combinadas, UBA). Profesora de Enseñanza Media y Superior en Artes (UBA). Profesora en el Departamento de Investigación y Producción de la Facultad de Diseño y Comunicación y en el Departamento de Ensayos sobre la Imagen, asignatura Teatro I (Universidad de Palermo). Docente en Historia de Teatro en diversos Institutos de Formación Actoral. 
Puedo tomar cualquier espacio vacío y llamarlo un escenario desnudo. Un hombre camina por este espacio vacío mientras otro lo observa, y esto es todo lo que se necesita para realizar un acto teatral

(Brook, 1973)

\section{Introducción}

Todo se desencadenó de este principio: el circuito oficial y comercial del teatro responde a modelos hegemónicos, a su vez, se identifica una ostensible producción de teatro y espacios independientes; sin embargo, surge el off del off como una forma espectral del circuito independiente. El objetivo del artículo es describir y articular un pensamiento crítico sobre la identidad del espacio teatral de la Ciudad. El punto nodal es la teoría de identidad de Paul Ricoer que piensa la identidad personal como una identidad narrativa. La hipótesis del ensayo descansa en la siguiente predicción: El 'circuito teatral' ya no puede definirse bajo la lógica del pensamiento binario. Es necesario recurrir al pensamiento deconstructivista para reflexionar sobre el espacio teatral actual.

En la primera parte del escrito se presenta el nacimiento y desarrollo histórico del teatro independiente en la Ciudad. En la segunda parte, se descomponen algunos principios teóricos nodales de la teoría de la Identidad articulada por Paul Ricoer. La tercera, hace foco en la teoría de Antonio Gramsci, descubriendo vínculos intrínsecos entre los tres espacios teatrales a través de la recuperación de ejemplos actuales de la cartelera teatral. Por último, a partir de una perspectiva deconstructivista, se visualiza el cruce entre los espacios teatrales. Desde ahí, se abandona la rigidez de la frontera entre los circuitos del teatro para aventurar intercambios múltiples.

\section{La campana de Leónidas Barletta}

Todo empezó con el grupo llamado de 'Boedo' (porque ocupaba un cuartucho en dicha barriada sur de la ciudad) que entró en conflicto, o no, con el denominado grupo 'Florida' (por tener su refugio literario en esa arteria elegante y central de la urbe), Los dos núcleos presentaban actitudes que podían estimarse igualmente como revolucionarias. La diferencia, fundamental para el caso, consistía en que mientras los de 'Florida' eran rebeldes en estética y se sentían ocupando una avanzada estrictamente literaria, los de 'Boedo', eran disconformes ideológicos y se empeñaban en impulsar la Revolución Social, ya triunfante, por entonces, en la antigua Rusia de los Zares. Mientras los de 'Boedo' creían firmemente y pugnaban por un teatro popular, los de 'Florida', cuando asomaba en ello la inquietud escénica, sólo aspiraban a lograr un escenario de arte, aunque sospechando, que por el momento, y debido a supuestas carencias en la materia, no podía ni pensarse en ello.

En el grupo 'Florida' se encontraban intelectuales como Evar Méndez, Eduardo González Lanuza, Oliverio Girondo y Jorge Luis Borges, entre las figuras capitales; en el de 'Boedo' participaban Alvaro Yunque, Elías Castelnuovo y Leónidas Barletta, y contaba con un gru- 
po de artistas plásticos modernos a cuyo frente se encontraban Guillermo Facio Hebequer y Abraham Vigo.

En 1903, Romain Rolland publicó en París su libro Teatro del Pueblo. Pero recién en 1927, se tradujo a nuestro idioma y apareció en Buenos Aires. Si bien no se disponía fácilmente, por entonces, de noticias respecto a las experiencias del 'nuevo teatro', que se estaban cumpliendo en la vanguardia europea, no era extraño que a quienes le interesaba el tema supieran de los trabajos que estaba realizando Antoine, Lugné-Poé y Erwin Piscator, Jacques Copeau, en Francia; Bragaglia, en Italia; Otto Braham en Alemania; H.T.Grein en Inglaterra; Stanislawski y Nemérovich-Dánchenko, en Rusia; Rivas Sherif y Valle-Inclán, en España, entre otros luchadores, a distinto nivel, por un nuevo teatro. De Europa llegaban los rótulos de Teatro Libre, Teatro Independiente, Teatro de Arte, Teatro Político, etc. En 1926, Octavio Palazzolo, que había sido agudo crítico teatral del diario La Vanguardia, era el director artístico de un elenco profesional con altas miras, pero que, al no resultar satisfactoria la recaudación, la empresa le exigía que cambiase el repertorio proyectado por obras de nivel menor para que fuera más rendidora la boletería. Palazzolo se negó y además, renunció a su puesto por entender, y así lo denunciaba en una nota, que "proseguir mis actividades en el teatro, aceptando una situación poco independiente, implicaba someterse a una claudicación vergonzosa y agotar un caudal de energías en una labor estéril" (Ordáz, 1992). Es la primera vez que se encuentra, en un documento referido a nuestro teatro, la palabra 'independiente', con una significación que se irá definiendo y ahondando con el correr de la lucha.

Al año siguiente (1927), Palazzolo se reunió con los escritores Alvaro Yunque, Elías Castelnuovo y Leónidas Barletta, y los artistas plásticos Facio Hebéquer y Abraham Vigo, todos de 'Boedo' - y conformaron el grupo denominado Teatro Libre. En la Declaración de Principios -inevitable, en estos casos-, se explicaba: "Aspiramos a crear un teatro de arte donde el teatro que se cultiva no es artístico; queremos realizar un movimiento de avanzada donde todo se caracteriza por el retroceso". Y aunque, siempre apasionado, señalaba en un reportaje: "En Buenos Aires, ya existe una cultura media que hace posible la subsistencia de un teatro que esté sobre la angurria del empresario, la vanidad de la actriz, la ignorancia del actor y la chatura del público burgués". Es de señalar cómo, a esta altura, iban asomando los conceptos que habrían de imponerse y serían bandera del ya inmediato "movimiento de teatros independientes" (Ordáz, 1992).

En la Biblioteca 'Anatole France' se formó en 1929, La Mosca Blanca. De este grupo, en 1930 se desprendió un nuevo elenco al que se denominó El Tábano (seguramente por la aseveración socrática popularizada por el diario Crítica) y se definía como Laboratorio de Teatro. A este grupo se le sumó Leónidas Barletta.

Al disolverse El Tábano, de vida muy corta, Barletta junto a otros fundó, el 30 de noviembre de 1930, el Teatro del Pueblo, el cual desde los inicios, se declaraba 'Agrupación al servicio del arte', y adopta como lema la frase de Goethe: "Avanzar sin prisa pero sin pausa, como la estrella". En 1931, luego de presentarse en la sala de la Wagneriana (Florida 936), el Teatro del Pueblo, se instaló en un cuchitril de la calle Corrientes angosta 465, número que, en la actualidad, corresponde a un edificio moderno de más de diez pisos.

Se proponía contrarrestar, con un repertorio de calidad indudable -en el que cabían todos 
los géneros, estilos y tendencias dramáticas, unidos clásicos y modernos- la labor funesta que estaban cumpliendo los escenarios porteños comercializados. Fue desde ese momento que empezaron a imponerse y flamear al tope, las tres banderas típicas de la escena libre: independencia de los empresarios, independencia de divas y capocómicos de turno, e independencia del rendimiento de la boletería.

Leónidas Barletta realizó con su Teatro del Pueblo una labor en verdad ciclópea. Desde el cuchitril de la calle Corrientes al 400 -para 120 espectadores posibles, sentados sobre toscos bancos de madera y telón de arpillera-, llegó hasta una sala teatral ya perfectamente conformada, como era la de Corrientes 1530. Pasó por los locales provisorios como los de Carlos Pellegrini 340 -donde nació el celebrado "teatro polémico", y Corrientes 1741, al que se la llamó el Corral de la Pacheta. La sala de Corrientes 1530 -que anteriormente había llevado los nombres de Corrientes y Nuevo-, en 1937 se denominó Teatro del Pueblo, transformándose, desde ese momento, en una auténtica Facultad de Humanidades, entrañablemente popular, sin exámenes de ingreso ni entrega de diplomas, pues los 'cursos' que se dictaban eran abiertos y libres, y no concluían nunca. La sala tenía capacidad para 1550 espectadores, no sólo se ofrecieron espectáculos teatrales y danza, sino también conciertos, exposiciones de variada índole, ciclos de conferencias y se editaron obras de teatro de autores nacionales; también se creó una revista: Conducta. A pesar de todo ello (o por todo ello, más exactamente), tras la Revolución de 1943, funcionarios reaccionarios se hicieron cargo de la Comuna Municipal porteña y, una de sus primeras tareas fue desalojar a Barletta y a su gente de la sala que, a partir de entonces, se llamó Teatro Municipal de la Ciudad de Buenos Aires. Una vez demolido el viejo edificio, y muy ampliado el predio, se construyó el modernísimo Teatro Municipal General San Martín.

Barletta y los suyos defendieron como tigres su teatro, hasta que finalmente sus puertas fueron forzadas por piquetes de policías y bomberos, cargándose en camiones municipales de basura, a granel, cuatro pisos de elementos -trajes, muebles, cuadros, focos, libros, etc- Barletta se cobijó con su gente en el subsuelo de la Diagonal Norte 943, en cuyo frente, hasta hace muy poco tiempo, había un pequeño cartel que anunciaba: Teatro del Pueblo. Al fallecer Barletta (1902-1975) la salita fue dedicada a exposición de artistas plásticos argentinos y, actualmente funciona el Teatro de La Campana. Es una bandera que rinde homenaje a la capacidad y al tesón de Leónidas Barletta. La historia cuenta y, hay testigos que dan fe de esta anécdota, que Leónidas Barletta se colocaba en la puerta del teatro, ubicado en Corrientes al 465 agitando una gran campana de bronce mientras hablaba. En ocasiones, la gente se acercaba para oír lo que proclamaba (Ordáz, 1992).

\section{La noción de identidad según Paul Ricoer}

Paul Ricoer entiende que la 'identidad' de un individuo o una comunidad está relacionada con responder la pregunta: ¿quién ha hecho esa acción? ¿Quién es su autor? La respuesta a la pregunta ¿quién?, es contar la historia de una vida. La historia narrada dice el quien de la acción. Por lo tanto, la propia identidad del quien es una identidad narrativa.

Ricoer teoriza la identidad a través de dos polos. Uno de estabilidad de la identidad al que llama, a través de un neologismo, la mismidad, que cubre todo aquello que da cuenta de 
una continuidad, de una estabilidad de la identidad y evoca, de alguna manera, al sentido clásico de la noción de identidad. Otro, el de la ipseidad que se corresponde con una promesa de sí mismo. Este último polo va a abrir el sentido de la palabra identidad a la idea de una identidad que no está nunca terminada y a la que él le da una suerte de sentido infinito (Robin, 1996, pp. 37-39).

La identidad narrativa está ubicada entre estos dos polos, entre la mismidad y la ipseidad. La noción de identidad narrativa permite pensar la noción de identidad personal. La identidad entendida en el sentido de un mismo (ídem), una identidad formal, se sustituye por la identidad entendida en el sentido de un sí mismo (ipse), una identidad narrativa. La identidad personal descansa en una estructura temporal que sigue el mismo modelo de identidad de la composición del texto narrativo. La identidad narrativa es la narración - escrita u oral- que una persona hace de sí misma y para sí mismo. Entonces la noción de identidad, implica la presencia de la ficcionalidad. La ficción señala que a pesar de que una persona no se mienta a sí misma, es absolutamente consciente de la dificultad de construir una verdad a partir de su propio relato.

Desde dicha perspectiva, la primera impresión permite visualizar un cruce entre la historia y la ficción. La historia se sirve de la ficción para configurar el tiempo. La ficción se sirve de la historia para reconfigurar los acontecimientos que podrían haber sido.

La posición de Aristóteles resulta oportuna para desarrollar la noción de reconfiguración del mundo. En su texto La Poética, define trama como la composición y disposición de los hechos y tragedia como la imitación de una acción. Ricoer hace una relectura señalando que el concepto de imitación no significa copia exacta de una acción de la realidad del referente 'real', sino que es una representación (volver a presentar) de una acción. De este modo, la acción se configura a través de una actividad mimética. La mímesis es la 'imitación creativa' de una acción de la realidad, es la operación que pone en funcionamiento un proceso creativo.

Ricoer desarrolla la teoría de las III Mímesis.

La Mimesis I es la preconfiguración del mundo. Sobre la precomprensión del mundo de referencia es desde donde se va a configurar la trama y la mímesis de la acción. En la Mímesis I se identifica la competencia previa, es decir, los saberes que se han adquirido sobre el mundo de la acción. El mundo de la acción es entendida como una red conceptual: la acción implica fines, remiten a motivos, tienen agentes que sufren y actúan en circunstancias, finalmente el resultado de la acción puede ser un cambio de suerte hacia la felicidad o la desgracia. Dominar esta red conceptual es tener una competencia práctica dentro del orden paradigmático ya que estos elementos son sincrónicos. En consecuencia, es necesario pasar a un orden sintagmático del discurso encarnando el carácter diacrónico de la narración con el fin de que los términos de la semántica adquieran integración y actualidad. Ricoer denomina a dicho proceso el primer anclaje. La integración convierte en compatibles los términos heterogéneos (agentes, motivos, circunstancias) y operan dentro de totalidades temporales efectivas. La doble relación entre reglas de construcción de la trama y términos de acción constituye una relación de transformación. La narración transforma a la acción. La actualidad ofrece a los términos que sólo tenían una significación virtual en el orden paradigmático una significación efectiva brindada por la articulación de la intriga. El segundo anclaje reside en los recursos simbólicos del campo práctico. Si la acción puede 
contarse es que ya está mediatizada simbólicamente. Las formas simbólicas son procesos culturales que articulan la experiencia. Cada acción tiene sentido porque pertenece a la red simbólica. El tercer anclaje es comprender en la acción estructuras temporales que exigen narración. La intratemporalidad rompe con la representación lineal del tiempo, entendida como sucesión de 'ahoras'. En la intratemporalidad se construirán las configuraciones narrativas y las formas más elaboradas de temporalidad.

La Mimesis II es la configuración del mundo, es donde se articula la configuración narrativa. Se abre el reino del 'como si', de la ficción. En esta mímesis se visualizan operaciones de configuración. La trama desempeña una función de mediación. En el acto configurante existen tres operaciones de mediación. La primera es que la trama media entre los acontecimientos y una historia tomada como un todo. La segunda es que la trama en la configuración propicia la integración de factores heterogéneos, articulando el paso del orden paradigmático al sintagmático. La tercera es que la trama es mediadora por sus caracteres temporales propios. La trama combina dos dimensiones temporales: una la cronológica, la dimensión episódica de la narración, la historia hecha de acontecimientos; la otra la no cronológica, la dimensión configurante propiamente dicha, los acontecimientos se transforman en historia.

El acto configurante de la construcción de la trama tiene dos rasgos complementarios. El esquematismo y la tradicionalidad que van a asegurar el transito de la Mímesis II a la Mímesis III. La esquematización es la unión entre el acto configurante y la imaginación creadora, produciendo el vínculo entre el entendimiento y la intuición. La imaginación es una facultad trascendental, no existe sin reglas. El esquematismo a través del lenguaje le da sentido a la imaginación. El esquematismo se constituye en una historia que tiene todos los caracteres de una tradición. La tradición tiene dos aspectos: la innovación y la sedimentación. La sedimentación se refiere a los paradigmas que constituyen la tipología de la trama. Estos paradigmas proceden de la historia sedimentada. Pero estos paradigmas nacen de una innovación anterior que proporcionan reglas. La imaginación creadora no nace de la nada, se relaciona con los paradigmas de la tradición. Cuando una obra teatral se aleja del paradigma tradicional provoca una desviación, una deformación. Sin embargo, estas desviaciones igualmente se convierten en reglas.

La Mímesis III es la reconfiguración del mundo. Ricoer habla de la relación entre poema y lector. En este artículo, se va a sustituir dicha relación por la de obra teatral y espectador. En ella se visualiza la intersección del mundo de la obra y el mundo del espectador. Es decir, la intersección del mundo configurado por la obra y el mundo del espectador en donde se despliega la acción, entendiendo por ello la totalidad de la obra. La construcción de sentido se produce cuando entran en relación el mundo configurado y el mundo del espectador. La obra dialoga con el espectador cuando se produce una identificación espacio temporal entre ambos mundos.

Por lo tanto, la Mímesis III es el rencuentro del mundo del espectador (mímesis I) con el mundo de la obra (Mímesis II).

En el campo teatral de la Ciudad de Buenos Aires se advierten tres circuitos teatrales: 'teatro comercial', 'teatro independiente', 'teatro off del off". Cada uno de ellos se autodefinen y proyectan una identidad personal entendida en el sentido de un sí mismo (ipse). La identidad personal descansa en una estructura temporal, especificada a través de las III 
Mímesis, que sigue el mismo modelo de identidad narrativa. Los tres circuitos son capaces de autoabastecerse y establecerse como espacios de expresión artística, fundamentando sus elecciones estéticas, exponiendo sus objetivos y propósitos, dando testimonio de sus procesos creativos, de sus tendencias, de su forma particular de asociar y de accionar, de su tipo de registro recurrente, de su modo de configurar la obra teatral. La identidad narrativa es la narración que cada uno de estos espacios hace sobre sí mismo y para sí mismo. Dentro de esta lógica, la noción de identidad, implica la presencia de la ficcionalidad. Los tres circuitos teatrales configuran un sí mismo, una identidad narrativa, una ficción que se materializa y se visualiza en una poética teatral determinada. La ficción señala que a pesar de que cada espacio teatral no se mienta a sí mismo, igualmente habilita una dinámica de enmascaramiento y desenmascaramiento de su propia identidad. La ficción señala la genuina dificultad de construir una verdad a partir de un relato. Una primera conjetura permite hacer la siguiente reflexión: El hecho teatral es una forma fantasmagórica en donde se materializa y se revela la identidad personal, más precisamente, la identidad narrativa de cada una de los circuitos que conviven en el campo intelectual teatral de la Ciudad de Buenos Aires.

Si en los circuitos teatrales se configura un mundo (Mímesis II) y se pone en funcionamiento la noción del 'como sî' que enciende la imaginación; los tres espacios teatrales construyen un mundo, un tiempo, un espacio y personajes propios. La identidad de los circuitos teatrales está relacionada con contar la historia del quién de la acción. Dicha narración es la responsable de abrir el sentido de la palabra identidad a la idea de una identidad que no está nunca terminada y a la que se le da un sentido infinito. Múltiples identidades, múltiples formas de expresarse conviven en la ciudad.

\section{Un fantasma recorre la ciudad: el fantasma del teatro off}

Buenos Aires es una de las capitales culturales del mundo. Los datos oficiales muestran que existen salas que dependen del gobierno de la ciudad como el Complejo Teatral de la Ribera, Teatro Presidente Alvear, Teatro Regio, Teatro San Martín, Teatro Sarmiento y del gobierno nacional como el Teatro Nacional Cervantes, denominados teatro oficial porque no persiguen lucro ya que son mantenidos por fondos del Estado. También cabe señalar, el Teatro Colón, el Centro Cultural Recoleta y el Centro Cultural Ricardo Rojas, este último dependiente de la Secretaría de Extensión y Bienestar Estudiantil de la Universidad de Buenos Aires.

Además, podemos identificar un circuito de teatro comercial compuesto por salas sostenidas por producción privada y destinadas al negocio teatral, es decir a la recaudación y la ganancia. Este tipo de teatro requiere de grandes inversiones para su realización y tiene como fin producir más dinero. Entre los teatros comerciales hegemónicos se encuentran el Metropolitan, el Astral, el Lola Membrives, el Gran Rex, el Maipo, el Paseo La Plaza, el Multiteatro, el Picadilly, el Premier, el Liceo, El Nacional, el Coliseo.

El circuito oficial y comercial del teatro responde a modelos legitimados y hegemónicos. Según Antonio Gramsci (1983, pp. 9-27) sentido común es la suma de pensamientos, de creencias, acumuladas en una determinada cultura, a lo largo de toda su historia. En el 
mismo están todas las ideas. Por lo tanto, en el sentido común habitan el circuito de teatro oficial, el circuito de teatro comercial y el circuito de teatro independiente. No obstante, existe una organización jerárquica del sentido común. La organización valorativa del sentido común está dada por la hegemonía. La hegemonía es la estructura ideológica, discursiva, estética que legitima el statu quo. Es una estructura que genera y garantiza que ciertas lecturas sean más previsibles que otras. La legitimidad está determinada por la hegemonía. Para que esta legitimación sea eficaz se presenta como una estructura ideológica natural. Se puede señalar que el circuito del teatro comercial se instala en grandes salas (más de 300 butacas), su objetivo es convocar un numeroso público para obtener una abultada recaudación. Las obras del teatro comercial generalmente pertenecen a escritores extranjeros consagrados y premiados, se pueden señalar algunas de ellas que forman parte de la cartelera actual: Buena Gente de David Lindsay - Abaire; Mineros de Lee Hall; Master Class de Terrence Mc Nally; Todos Felices de Alan Ayckbourn; Filosofía de vida de Juan Villoro; La Cabra de Edward Albee, etc. Dichas obras coinciden en convocar a actores del cine, teatro y televisión, altamente consagrados, premiados y populares, en la cartelera de hoy conviven, por ejemplo: Mercedes Morán, Gustavo Garzón, Julio Chavez, Claudio Lapacó, Hugo Arana, Juan Leyrado, Dario Grandineti, Jorge Marrale, Norma Aleandro, Carola Reyna, Rodolfo Bebán, Alfredo Alcón, entre otros.

El primer recurso de la hegemonía es naturalizar la ideología. La hegemonía es una estructura ideológica que se manifiesta en lo estético, en lo discursivo y en lo retórico ya que estos resultan ser modos altamente eficaces para naturalizarla. La hegemonía es una estructura ideológica que se articula desde el poder, es decir, desde la ideología dominante. Naturalizar determinadas estéticas permite crear un hábito dentro del sentido común.

La identidad del circuito de teatro comercial se desarrolla a partir de responder la pregunta: ¿quién? La respuesta exige contar la historia de una comunidad teatral. La historia narrada dice el quien de la acción. Cuando se hace foco en el teatro comercial se observa que la combinación de obras, actores, directores consagrados y premiados crean una fórmula efectiva a la que se nomina con la expresión teatro comercial de arte. En ese circuito se articula una copiosa recaudación con exigencias artísticas de primer nivel y calidad destacable. El teatro comercial pertenece a importantes y reconocidos productores teatrales que cuentan con un generoso aparato de promoción, difusión y publicidad capaz de naturalizar una determinada estética convirtiéndola en hábito para el espectador.

En una primera impresión, el teatro comercial ocupa el centro de la comunidad teatral, es decir, un lugar hegemónico que se configura a partir de una determinada estética, actores, directores y dramaturgos.

Desde la perspectiva del pensamiento binario, el signo lingüístico según Saussure funciona mediante oposiciones, el significante se construye en contraposición a los demás incluidos en el sistema. Esta estructura puede definirse como un sistema de diferencias y analogías. El pensamiento binario de Saussure se articula en la noción de signo. El signo es una entidad psíquica configurada por dos partes indisociables: el significado / el significante (Pavis, 2000, p. 29).

La lógica de este pensamiento indica que si hay un centro, hay una periferia. Antonio Gramsci habla de hegemonía y hegemonía alternativa. 
En la Capital Federal conviven junto con los teatros del circuito teatral comercial más de doscientos espacios que conforman lo que se denomina el circuito de teatro independiente. El sesenta por ciento de estos espacios funcionan en sitios no convencionales. Si en el sentido común está todo, también está aquello que contradice la hegemonía. La contradicción de la hegemonía no está fuera del sentido común. Por consiguiente, dentro del campo intelectual teatral se puede identificar al teatro independiente como un teatro que manifiesta contradicciones. La deconstrucción de la hegemonía se produce a partir de la construcción de la hegemonía alternativa. La hegemonía alternativa es una estructura ideológica, discursiva, estética que permite reorganizar los relatos hasta ahora naturalizados. Se induce que podemos ubicar el teatro independiente como una hegemonía alternativa que explicita y evidencia las voces marginadas del teatro.

Dentro de este contexto, la Asociación de Cronistas del Espectáculo entrega el premio ACE a la producción teatral. Resulta curioso descubrir que existen rubros para mejor actor, actriz, director, espectáculo conviviendo con los de mejor actor, actriz, director, espectáculo alternativo. Dicha escisión entre alternativo y no alternativo, que no está dicha sino sólo por omisión, permite conjeturar que hay actores, directores, dramaturgos del teatro independiente y otros del teatro comercial. Pero, ¿se puede pensar que hay un oficio de actor y un oficio de actor alternativo?...

Asimismo, se puede observar una diferencia en la dinámica de las funciones. El teatro comercial ofrece funciones de miércoles a domingo, es probable que en algunas salas el sábado exista una doble función. Esta estructura refleja uno de los problemas del hecho teatral que es el de la repetición. Con el incremento de las funciones, la repetición niega lo vivo porque evoca el aspecto mecánico del proceso de la representación. El actor tiene que renacer cada función al personaje que, inexorablemente, se va erosionando de a poco a causa de la mecanización. La técnica del actor es la herramienta más efectiva para sortear este obstáculo y mantener vivo en el aquí y ahora el acontecimiento teatral.

No obstante, el teatro independiente se aleja, ostentosamente, de esa propuesta ya que una pieza teatral tiene, casi como excepción, no más de dos funciones por semana. En el circuito independiente, en un día, en una sala, conviven por lo menos dos obras de teatro diferentes, dos elencos distintos. Esta dinámica sortea la dificultad de la repetición en el teatro pero pone en escena otra problemática. Una función por semana implica que el actor se aleja del material, del personaje, del espacio, de los estados durante casi siete días. Cada función pone al actor en una situación similar a la del estreno, a veces se ensayan fragmentos de la pieza, se repasa el texto o los movimientos antes de la representación, se hace un precalentamiento para acercarse al espacio y al material desde un canal creativo y de experimentación. Si bien no se va profundizar sobre este asunto, estas dos dinámicas diferentes de atravesar el hecho teatral son fundante en relación al trabajo del actor dentro de un proceso creativo.

Resulta pertinente enumerar dentro del circuito de teatro independiente algunas de las numerosas salas privadas. Sus dueños no son empresarios importantes, tampoco es el Estado, sino artistas en ejercicio o fuera del mismo, por ejemplo: El camarín de las musas, Teatro Beckett, El Kafka, El Portón de Sánchez, Teatro Anfitrión, Teatro del Abasto, Teatro El Extranjero, Timbre 4, Espacio Callejón, La Carpintería, La Carbonera, El excéntrico de la 18, Puerta 
Roja, Sportivo Teatral, Pata de Ganso, Patio de Actores, etc. Algunos de los directores de este espacio independiente son: Julio Chavez, Rafael Spregelburg, Ruben Szuchmacher, Maruja Bustamante, Berta Goldemberg, Román Podolsky, Walter Jakob y Agustín Mendilaharzu, Claudio Tolcachir, Romina Paula, Diego Lerman, Daniel Veronese, Javier Daulte, etc.

Del mismo modo que en el teatro comercial, la noción de identidad del circuito de teatro independiente se desarrolla a partir de responder la pregunta: ¿quién?, ¿quién es el autor? También, la respuesta exige contar la historia de una comunidad teatral. La historia narrada dice el quién de la acción. Cuando se hace foco en el teatro independiente se observa que la combinación de obras, actores, directores que habitan el espacio independiente configuran dicho espacio. Sin embargo, detectamos algunos artistas que habitan ambos circuitos de teatro, por ejemplo: Julio Chavez, Ruben Szuchnacher, Claudio Tolcachir, Daniel Veronese, Javier Daulte, entre otros.

Entonces se puede inferir que si el ¿quién? es el mismo, ¿la historia narrada que hace foco en el quien de la acción será la misma? La segunda impresión descubre que la propia identidad del quién es una identidad narrativa que habilita ciertos cruces intrínsecos entre poéticas que pueden habitar el teatro comercial y el teatro independiente simultáneamente. Queda por añadir el concepto de Bourdieu que define el Campo Intelectual como un campo magnético capaz de constituir un sistema de líneas de fuerza: esto es, los agentes o sistemas de agentes que forman parte de él y que pueden describirse como fuerzas que, al surgir, se oponen y se agregan confiriéndose su estructura específica en un momento dado del tiempo. El campo intelectual es un espacio social. El campo intelectual es el espacio social en donde se insertan los productores y los productos de la cultura. Tiene una estructura específica y es portador de una autonomía relativa dentro de la sociedad, autonomía regida por sus propias leyes. Este espacio social establece sus propias instancias de selección, consagración, formación y difusión cultural. Las instituciones formadoras consagran a partir de su autoridad e imponen normas (sistema escolar, academias, institutos, etc.) Las instituciones legitimadoras guían culturalmente (grupos literarios, artísticos, círculos de críticos, fundaciones, institutos, asociaciones, etc). Dichas instituciones imponen sus normas culturales al campo intelectual. El capital legítimo lo conforman los productos y productores que habitan el campo intelectual, denominado el capital cultural. La posición de un artista en el capital cultural define su posición dentro del campo. Un artista puede alejarse o acercarse del capital cultural legitimado dentro de una sociedad. Cada posición de un artista en el campo se define también por su relación con los demás, con los demás artistas, con las instituciones oficiales y privadas (Bourdieu, 1967, pp.135-182).

En la actualidad, el Instituto Nacional del Teatro, Proteatro y el Fondo Nacional de las Artes subsidian proyectos teatrales independientes, además algunos de esos teatros independientes pertenecen a ARTEI (Asociación Argentina del Teatro Independiente).

Por esta razón, las producciones independientes portan de una autonomía relativa, regida por las propias leyes de selección de estas instituciones. Las mismas consagran las obras a partir de su autoridad dentro del campo intelectual otorgándole un valor que les permite a las mismas conformar el capital cultural de la sociedad.

Dicho argumento muestra como el término independiente articulado por Leónidas Barletta queda desfasado. En la antigüedad el término independiente se concibe en el seno de 
un grupo de artistas que tienen la intención de funcionar completamente autónomos de cualquier institución legitimadora. Luis Ordáz recuerda una anécdota que da testimonio de esto: en 1926, Octavio Palazzolo, que había sido agudo crítico teatral del diario La Vanguardia, era el director artístico de un elenco profesional con altas miras, pero que, al no resultar satisfactoria la recaudación, la empresa le exigía que cambiase el repertorio proyectado por obras de nivel menor para que fuera más rendidora la boletería. Palazzolo se negó y además, renunció a su puesto por entender, y así lo denunciaba en una nota, que "proseguir mis actividades en el teatro, aceptando una situación poco independiente, implicaba someterse a una claudicación vergonzosa y agotar un caudal de energías en una labor estéril".

En la actualidad, es oportuno transformar el término de teatro independiente en teatro alternativo. Si bien es cierto que el circuito independiente pasa a ser una actividad que se contrapone a los circuitos oficiales y comerciales aceptados, la política de subsidios no permite que se produzca de forma autónoma. Es cierto que la modalidad de trabajo de este tipo de teatro es a partir de la generación de cooperativas y de la formación de grupos autogestionados. Sin embargo, no basta para conseguir una independencia y autonomía con las instituciones legitimadoras.

Por último, se puede observar dentro del teatro alternativo un nuevo circuito denominado off del off que surge como una forma espectral del circuito alternativo. Los espacios son viviendas de los directores y actores, galpones, fábricas abandonadas u otros lugares que no cumplen con los requisitos de habilitación de un teatro. Funcionan como espacios de experimentación, creación y reflexión de lenguajes estéticos.

Es sabido, que las inhabilitaciones de espacio de artes escénicas que se produjeron al revisar la normativa vigente tras los hechos trágicos acontecidos en los últimos años ( $\mathrm{La}$ Tragedia de Cromañon) ponen de relieve una discusión que la gestión de políticas públicas no ha sabido llevar a cabo acerca de la actividad teatral. Cabe enumerar algunas salas a las que podemos considerar como referentes de el off del off: Elefante, Vera Vera, El Crisol, Polonia, Escalada, Teatro del Perro, Defensores de Bravard, Guapachoza, Cámara de Teatro, La Castorera, Ladran Sancho, El Brío, Abrancancha, Brilla Cordelia!, Club Cultural Matienzo, El Pacha, El Paraíso, Granate, Machado, Oeste Estudio Teatral, Querida Elena sencillas artes. Algunas de estas salas no incluyen su dirección cuando proponen una puesta en escena y el teléfono que aparece puede ser un celular. Llegar a ellas implica un complejo recorrido por cierto universo teatral que requiere una información relativamente cerrada y acotada a un círculo (Bordegaray, 2010, pp. 40-42).

En junio del 2010, un grupo de dueños de espacios alternativos comenzaron a agruparse bajo el nombre de Escena o Espacios Escénicos Autónomos. Escena empezó a organizarse en reuniones plenarias conformando cuatro comisiones de trabajo: Ley, Prensa, Festival, Compras y subsidios. Escena surge en una primera reunión convocada por el Colectivo escena, ex Colectivo teatral. Colectivo teatral era una organización que tenía como fin reflexionar y accionar sobre las problemáticas de las expresiones escénicas de la Ciudad de Buenos Aires. Colectivo teatral, decide organizar un encuentro con todas aquellas salas que se encuentren en situación de clandestinidad o poco clara. Paralelamente, Colectivo teatral cambia su nombre a Colectivo escena. 
A partir de las acciones realizadas por Espacios Escénicos Autónomos se obtuvo la sanción y promulgación de la ley 3707 que autoriza a estos espacios a funcionar con la iniciación del trámite de habilitación. La nueva norma rescata de la clandestinidad a una cierta cantidad de salas.

En diálogo con IPS (Inter Press Service), Martín Seijo, integrante de Escena, explica que los costos de acondicionar una sala para que sea habilitada son tan altos que si el proyecto no tiene un perfil empresarial tiene que cerrar sus puertas. Explicaba: "Acá los dueños son actores o directores que tienen estas salas como lugares de experimentación, para crecer en la producción estética y para reflexionar sobre la propia práctica” (Valente, 2011).

Rubén Sabadini, integrante de Espacios Escénicos Autónomos, cuenta en una entrevista que realizó para Alternativa Teatral que organizaron el primer Festival Escena en quince días, la publicidad fue hecha en una fotocopia en A3. El resultado fue extraordinario, los espacios se llenaron de espectadores. Del 17 de septiembre al 8 de octubre del 2011 se lleva a cabo la segunda edición del Festival Escena, en esa oportunidad, coincidiendo con el VIII Festival Internacional de Buenos Aires (FIBA).El Festival Escena se propone difundir en forma conjunta las obras que se exhiben en los Espacios Escénicos Autónomos de la Ciudad. Estas salas ofrecen su programación con una entrada accesible y unificada. Además, hay talleres, charlas abiertas, espacios compartidos y la presentación de un proyecto colectivo de intervenciones en todos los espacios participantes del evento Mapa Escena (Escena, 2011).

En paralelo, el viernes 8 de junio del 2012 ARTEI Teatro Independiente publica en su página de Facebook lo siguiente:

ARTEI informa que en asamblea del día de la fecha, se ha decidido realizar una convocatoria extraordinaria a las salas asociadas, a la comunidad teatral en general y a la prensa para el día martes $12 / 6$ a las $16 \mathrm{hs}$, en el teatro Abasto Social (Yatay 666).

Dicha convocatoria se realiza con el fin de reafirmar la campaña solidaria a favor de la sala Abasto Social Club (injustamente perjudicada por el Instituto Nacional Del Teatro) e informar sobre el avance de la misma como así también esclarecer de manera más detallada sobre este problema que nos afecta a todos.

Aprovechamos para agradecer a la gran cantidad de salas e integrantes de la comunidad teatral que han colaborado hasta la fecha así como el apoyo solidario de la prensa en la difusión de esta alarmante situación Los esperamos el martes 12 a las 16hs. en el Teatro Abasto Social Club (Yatay 666). ARTEI; Asociación Argentina del Teatro Independiente. (https://www.facebook.com/arteiteatros)

Asimismo, el mismo día ARTEI había pedido una entrevista con carácter de urgente al Ministro de Cultura de la Ciudad, así lo anunciaba: 
Informamos a las salas asociadas y a la comunidad teatral, que en la última asamblea ARTEI se decidió enviar una carta de pedido de entrevista con carácter de urgente al Ministro de Cultura de la Ciudad. Ing. Hernán Lombardi como así también al Dr. Juan Manuel Beati, Director Administrativo de PROTEATRO, a fin de manifestar nuestra profunda preocupación por el retraso en los pagos de los subsidios para salas cuya convocatoria cerró el 15 de febrero. Teniendo en cuenta de el Directorio de dicho organismo evaluó, aprobó y dio curso a los expedientes en tiempo y forma, es inadmisible que el Ministerio de Cultura se encuentre demorando el pago de los mismos sin motivo alguno (ARTEI. Asociación Argentina del Teatro Independiente).

Con todo, se puede distinguir algunos ejemplos que cooperan para evidenciar intercambios extraordinarios entre los diferentes espacios teatrales: Matías Feldman es fundador de Defensores de Bravard, sala perteneciente a Escena. Sin embargo, en el 2011 estrena en el circuito oficial, en el Teatro Sarmiento, la obra Hacia donde caen las cosas de su autoría y dirección. Rubén Sabadini es fundador del Teatro Vera Vera, sala que también pertenece a Escena. Del mismo modo, en el 2012 actúa en la obra La Cita que tiene autoría y dirección de Aldana Cal, en el Teatro Beckett, sala del circuito independiente que goza de su habilitación. Alberto Ajaka es fundador del teatro Escalada, sala que integra el mapa Escena. En el 2012 estrenará, como actor, en el Teatro General San Martín, teatro oficial, la pieza Macbeth de William Shakespeare dirigida por Daniel Daulte. Una perlita más, la obra teatral escrita y dirigida por Ciro Zorzoli Estado de ira que se estrenó en el espacio oficial, en el Teatro Sarmiento, hoy es parte de la cartelera del circuito comercial, con funciones los lunes en el Teatro Metropolitan.

Siguiendo con la línea del pensamiento de Ricoer se puede inferir que el ¿quién? es el mismo que transita el teatro oficial, el teatro comercial, el teatro independiente y el teatro off del off sin solución de continuidad. Entonces, la historia narrada que hace foco en el quien de la acción será la misma. La tercera impresión centra la atención en imaginar que la propia identidad del quién es una identidad narrativa que en lo fáctico habilita cruces intrínsecos entre poéticas, la identidad del quién transita dos, más o todos los circuitos teatrales de la Ciudad, hasta en algunos ejemplos simultáneamente.

\section{El espacio espectral, el off del off}

Existe algo extraño en la categoría off del off. Desde el enfoque del pensamiento binario se puede suponer que si hay un off del off implica que primero hay un off que se define por oposición a un on. Se sabe que una de las acepciones del vocablo en inglés on es encendido. Por lo tanto, por oposición off significa apagado. Por consiguiente, off del off designa algo que se apaga dos veces. Pero eso resulta imposible porque... ¿algo se puede apagar dos veces? No. Se dice: No se puede.

Si alguna vez hubo un off Corrientes eso ha quedado caduco en el tiempo porque hoy se puede decir que hay un off Corrientes en la propia Corrientes. Si Corrientes era el circuito 
on, un espacio encendido, se debe a que gozaba de una luz propia capaz de delinear el centro del campo intelectual de la Ciudad. Sin embargo, en la actualidad, esta lógica es impropia porque hay salas del off en la calle Corrientes. Resulta sorprendente pensar que dentro de la calle on, la calle encendida por las luminarias de los teatros, se pueda localizar un off, un espacio que por definición parecería apagado, ausente pero paradójicamente presente. Por ende, el teatro off aglutina la dialéctica ausencia/presencia.

Resulta adecuado servirse del pensamiento de Derrida para comprender la lógica del espectro como una paradoja. En su texto Los espectros de Marx (1995, pp. 11-52) define al espectro como algo que no se sabe qué es, no se sabe si existe.

El espectro:

- no es carne, ni hueso, ni cuerpo, ni espíritu, Pero a su vez, una y otra cosa.

- es un no-objeto, es algo innombrable o casi innombrable, "eso", algo indecible.

- está presente pero no está presente.

- es la presencia de una ausencia. Es un re aparecido, es un muerto que regresa. Es una (re) aparición de lo ausente.

- no está ni vivo ni muerto

- Está ahí pero no está ahí

- Deviene cuerpo pero no es cuerpo

El espectro es una cierta cosa difícil de nombrar: no es ni espíritu, ni cuerpo. Pero a su vez, una y otra. Es una cierta forma fenoménica y carnal del espíritu. El espectro inaugura un área de indecibilidad. Derrida realiza un movimiento deconstructivo. La deconstrucción es un movimiento de descentramiento, es la localización de un área de indecibilidad. El espectro resulta indecible entre dos extremos cuerpo y espíritu. Esta indecibilidad es la que define al espectro.

El off del off se instala en el espacio teatral como una manifestación fantasmagórica del teatro alternativo. El off del off provoca la ruptura del equilibrio garantizado por el pensamiento binario que se ciñe en la tensión circuito comercial / circuito alternativo. El off del off resulta indecible entre dos. Por lo tanto, el off del off promueve, accidentalmente, la inauguración de un área de indecibilidad en el espacio teatral de la Ciudad.

El pensamiento de deconstrucción, de descentramiento se extiende al campo intelectual teatral de la Ciudad en la actualidad. Los representantes del circuito oficial, comercial, alternativo, off del off, franquean y atomizan la idea de límite y frontera. La frontera entre lo hegemónico (teatro oficial y comercial), lo hegemónico alternativo (teatro alternativo), y lo fantasmagórico (Teatro off del off) es pulverizada por la realización. Es probable que la idea de frontera pueda existir todavía como un límite real en el universo conceptual pero ya no en la experiencia vital del hecho teatral.

A modo conclusivo, en un primer ensayo, se cruza esta línea de reflexión con el pensamiento de Zizek (2006). Para él es imposible el cierre del orden simbólico, esta incapacidad de cierre es algo constitutivo del orden simbólico. Cuando se desintegra la frontera, inevitablemente, se abre una brecha, un 'entre dos' posibilidades:

- La primera asociada a la idea de 'circuito oficial'

- La segunda pensada a la noción de 'circuito alternativo' 
Zizek a esta brecha la denomina Brecha de Paralaje, esto es un aparente desplazamiento de un objeto causado por el cambio de posición de un sujeto. La naturaleza del objeto cambia con el desplazamiento. El desplazamiento abre una brecha entre un punto y el otro.

Se observa que el objeto 'circuito teatral' sufre un aparente desplazamiento causado por el cambio de posición del sujeto, del quién, los artistas. Este desplazamiento permite abrir una brecha de paralaje entre un punto y el otro modificando al objeto circuito teatral. De esta forma, se abre una brecha entre dos extremos: circuito comercial / circuito alternativo. Sobre esta dislocación interna se funda, nuevamente, la noción de circuito teatral.

El circuito teatral ya no puede definirse bajo la lógica del pensamiento binario. Es necesario recurrir al pensamiento deconstructivista para reflexionar sobre el espacio teatral actual. A primera vista, el circuito teatral se puede definir como un espacio de acción, del hacer, de la producción y de múltiples formas de expresión, que se chocan, se cruzan, conviven, se enfrentan, dialogan, se nutren, se potencian y coexisten en la Ciudad.

Por último, traspasar la idea de límite y frontera aventura la oportunidad de un porvenir que reactiva el intercambio real y experimental. Abandonar las categorías hasta ahora legitimadas que nominan los distintos circuitos teatrales permite la apertura a lo otro, es decir, a múltiples identidades. El campo teatral promete abrir el sentido de una nueva idea de identidad, una identidad que nunca está terminada y a la que se le puede augurar un sentido infinito.

En la actualidad, múltiples identidades recorren el espacio teatral de la Ciudad de Buenos Aires, son las múltiples identidades narrativas teatrales. Ciertos hechos teatrales iluminan al espectador, otros explican su mensaje y algunos sencillamente dicen 'estoy aquí y ahora'

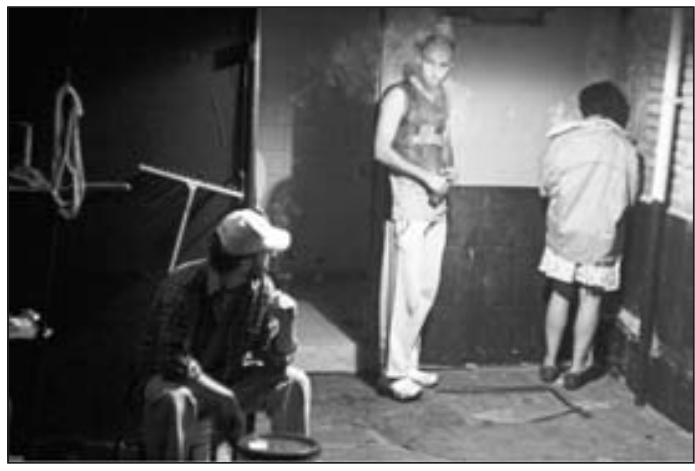

Figura 1. Plantas secas en la calle White de Melina Knoll. Dirección: Valeria Grossi. Abasto Social Club. (2012). Sala actualmente inhabilitada por el Instituto Nacional del Teatro. Fuente. Valeria Grossi. 


\section{Bibliografía}

ARTEI Asociación Argentina del Teatro Independiente. 8 de junio del 2012. Disponible en: https://www.facebook.com/arteiteatros

Berman, M. (2010). El off. Primera Parte. Funámbulos, 32, 37/39.

Bordegaray, L. (2010). El off. Segunda Parte. Funámbulos, 32, 40/42.

Bourdieu, P. (1967). Campo Intelectual y Proyecto Creador. En: Povillon, J. y otros: Problemas de estructuralismo. México: Editorial Siglo XX.

Brook, P. (1973). El espacio vacío. Arte y técnica del teatro. Barcelona: Ediciones Península. Derrida, J. (1995). Espectros de Marx. Madrid: Editorial Trotta.

Escena: Espacios Escénicos Autónomos. Recuperado Febrero 2012. Disponible en: http:// espaciosescenicosautonomos.blogspot.com/2011/01/contacto.html

Gramsci, A. (1983). Introducción a la filosofía de la praxis (Escritos dos). México: Premia Editora.

Madedo, F. (2011). ¿Qué hacer con la actividad teatral? Montaje Decadente, 2, 23.

Ordáz, L. (1992). Leónidas Barletta: El hombre del teatro. Buenos Aires: Teatro del Pueblo. Recuperado Febrero 2012. Disponible en: http://www.teatrodelpueblo.org.ar/dramatur gia/ordaz003.htm

Pavis, P. (2000). El análisis de los espectáculos. Barcelona: Paidós.

Robin, R. (1996). Identidad, memoria y relato de sí mismo. Buenos Aires: Oficina de Publicaciones Ciclo Básico Común.

Sabadini, R.; Barbato Onofri, J. (2011). ¿Qué es escena? Buenos Aires: Alternativa Teatral T.V N¹6. Disponible en: http://www.alternativateatral.com/video1251-alternativa-teatral-tv-16-que-es-escena

Valente, M. (2011). El off del off. Buenos Aires: IPS (Inter Press Service). La conexión global. Recuperado Febrero 2012. Disponible en:http://ipsnoticias.net/nota.asp?idnews=975 Zizek, S. (2006). Wisión de Paralaje. México: Fondo de Cultura Económica.

Summary: Buenos Aires is one of the cultural capitals of the world. Official data show that there are six official theaters, twelve private theaters and more than two hundred commercial and independent theater spaces, of which more than seventy percent runs in unconventional places. According to Antonio Gramsci, hegemony is an ideological structure, discursive, aesthetic that legitimizes the status quo, in a historic, political and cultural context. Therefore, hegemony legitimate certain expressive ideologies and discourses over others. Official and commercial circuits responds to a hegemonic theater model. However, theater productions and independent spaces are significant. It is necessary to reformulate the concept of 'independent' theater of Leonidas Barletta. Nowadays, the National Theatre Institute, Proteatro and the National Art Foundation provide the funds for independent theater projects. Therefore, they carry a relative autonomy, governed by the laws of selection of these institutions, becoming 'alternative' rather than 'independent'. The off 
of the off theater arises as a spectral shape of the "alternative" circuit. These theaters are homes of directors and actors, warehouses or other places that do not meet the enabling requirements for a theater. The aim of this paper is to describe and articulate critical thinking about the identity of the City theater space. The nodal point is the identity theory of Paul Ricoer who conceives personal identity as a narrative identity. The article hypothesis rests on the following prediction: The 'theater circuit' can not be defined under the logic of binary thinking. It is necessary to use the deconstructivist thought to reflect on the current theater space.

Keywords: alternative theater - commercial theater - hegemony - identity - independent theater - legitimizing institutions - multiple identities - narrative identity - off of the off theater - official theater - Parallax Gap - spectral shape.

Resumo: Buenos Aires é uma das capitais culturais do mundo. Os dados oficiais mostram que existem seis salas que dependem do Estado, doze salas privadas comerciais e mais de duzentos espaços de teatro independente, dos quais mais do setenta por cento funcionam em lugares não convencionais. Segundo Antonio Gramsci, a hegemonia é uma estrutura ideológica, discursiva, estética que legitima o statu quo, num momento histórico, político e cultural determinado. Portanto, a hegemonia legitima certas ideologias e discursos expressivos por acima de outros. O circuito oficial e comercial do teatro responde a modelos hegemônicos. No entanto, se identifica uma visível produção de teatro e espaços independentes. É necessário reformular o conceito de teatro independente de Leónicas Barletta. $\mathrm{Na}$ atualidade, o Instituto Nacional do Teatro, Proteatro e o Fundo Nacional das Artes subsidiam e financiam aqueles projetos teatrais independentes. Assim, eles portam uma autonomia relativa, regida por as leis de seleção destas Instituições, transformando-se em alternativos mais que em independentes. O off do off surge como uma forma espectral do circuito alternativo. Os espaços são vivendas dos diretores e atores, galpões ou outros lugares que não cumprimentam os requisitos de habilitação de um teatro. O objetivo do artigo é descrever e articular um pensamento crítico sobre a identidade do espaço teatral da Cidade. O ponto nodal é a teoria de identidade de Paul Ricoer que pensa a identidade pessoal como uma identidade narrativa. A hipótese do ensaio descansa na seguinte predição: o circuito teatral já não pode definir-se na lógica do pensamento binário. É necessário recorrer ao pensamento deconstrutivista para reflexionar sobre o espaço teatral atual.

Palavras chave: brecha de Paralaje - forma espectral - hegemonia - identidade - identidades narrativas - instituições legitimadoras - múltiplas identidades - teatro alternativo - teatro comercial - teatro independente - teatro off do off - teatro oficial. 